\title{
Effects of total aerosol on temperature and precipitation in East Asia
}

\author{
Jian $\mathrm{Wu}^{1,2, *}$, Congbin $\mathrm{Fu}^{2}$, Yanyan $\mathrm{Xu}^{3}$, Jianping Tang ${ }^{4}$, Zhiwei Han ${ }^{2}$, Renjian Zhang ${ }^{2}$ \\ ${ }^{1}$ Department of Atmospheric Science, Yunnan University, Kunming 650091, PR China \\ ${ }^{2}$ Key Laboratory of Regional Climate-Environment Research for Temperate East Asia, Institute of Atmospheric Physics, \\ Chinese Academy of Sciences, Beijing 100029, PR China \\ ${ }^{3}$ Yunnan Meteorological Bureau, Kunming 650031, PR China \\ ${ }^{4}$ Department of Atmospheric Science, Nanjing University, Nanjing 210093, PR China
}

\begin{abstract}
Numerical simulations were conducted for 1960-2000 to estimate the direct effects of aerosols on temperature and precipitation in East Asia. Radiative forcing and regional climatic effects of total combined aerosol — including sulfate, dust, black carbon, and organic carbon — over the East Asian region were investigated using the NCAR Community Atmospheric Model, Version 3.1. Surface dimming is revealed by the simulated negative radiative forcing at the surface, and the most distinct dimming can exceed 30 and $25 \mathrm{~W} \mathrm{~m}^{-2}$ under clear and all sky conditions, respectively; dimming cools the surface by $1.5 \mathrm{~K}$ in most regions in the study domain. Air column temperatures increase in northern India and northwestern and northern China, and decrease in other areas. The profiles of air temperature show similar trends in different areas, with a decrease below $850 \mathrm{hPa}$ and an increase in the middle of the troposphere. The finding of increases in vapor content and precipitation in northern and northwestern China contradicts recent trends of flooding in the south and drought in the north of China, which have been attributed to the effects of aerosol absorption in some simulation studies. In our study, significant precipitation increases by a maximum of $9 \%$ in northern and northwestern China, while it decreases by up to $12 \%$ in the southern part of the Tibetan Plateau, the Sichuan Basin, and most of southern, southeastern, and northeastern China.
\end{abstract}

KEY WORDS: Sulfate · Black carbon • Organic carbon · Dust · Direct effects • Temperature • Precipitation

Resale or republication not permitted without written consent of the publisher

\section{INTRODUCTION}

The global mean direct radiative forcing (RF) induced by aerosol lies around $-0.5 \pm 0.4 \mathrm{~W} \mathrm{~m}^{-2}$ (Forster et al. 2007). The RF of aerosol-contributions from sulfate, black carbon (BC), organic carbon $(\mathrm{OC})$, and dust-is lower than that of carbon dioxide, which is $1.66 \pm 0.17 \mathrm{~W} \mathrm{~m}^{-2}$, but it is sufficient to affect the climate.

Some studies in China report the main ingredients of aerosol as sulfate, dust, $\mathrm{BC}, \mathrm{OC}$, and sea salt (He et al. 2001, Xu et al. 2002, Ye et al. 2003, Han et al. 2008). Aerosol over most of Asia is close to Atmospheric Brown Cloud (ABC) characteristics (Ramanathan et al.
2007 a), roughly $75 \%$ of which is of anthropogenic origin (Ramanathan et al. 2001).

$\mathrm{ABC}$ with a visible absorption optical depth as low as 0.02 is sufficient to enhance solar heating of the lower atmosphere by as much as 50\% (Ramana et al. 2007, Ramanathan et al. 2007b). Over most of East Asia, the annual mean excessive solar heating in the atmosphere exceeds $10 \mathrm{~W} \mathrm{~m}^{-2}$, and over the $\mathrm{ABC}$ hotspots it exceeds $15 \mathrm{~W} \mathrm{~m}^{-2}$ (Jayaraman et al. 2006). The amount of direct and global solar radiation reaching the surface has decreased in many regions of China during the past half century (Luo et al. 2001, Xu et al. 2001, Liang \& Xia 2005, Qian et al. 2006, 2007). Similar dimming has been reported in South Asia (Vinoj et al. 2004, Dumka et al. 2006). 
The earliest study of aerosol effects on temperature in East Asia using regional climate models (RCMs) considered only the direct effect of sulfate (Qian \& Giorgi 1999). Later, a chemistry model was coupled into RCMs and the effects of several aerosol types were simulated (Giorgi et al. 2002, 2003, Qian et al. 2003, Wang et al. 2003). Giorgi et al. (2002) found that the simulated temperature trends induced in China by sulfate and soot were consistent with observations in recent decades. Giorgi et al. (2003) demonstrated that under current sulfur emissions, direct effects of anthropogenic sulfate are the most important during the cold season, while indirect effects dominate in the warm season. Qian et al. (2003) used an RCM driven by offline aerosol data from a global chemistry-aerosol model to simulate the effects of aerosols on climate over East Asia. Their results indicate that a negative RF induces surface cooling, mainly due to the decrease in maximum temperature during the daytime. Huang et al. (2006) investigated the second indirect effect of aerosol and found that the diurnal temperature range decreases by $-0.7^{\circ} \mathrm{C}$ in the industrialized parts of China.

Changes in precipitation in China have distinctive regional and seasonal patterns (Zhai et al. 2005), especially for the significant decreases of annual total precipitation in northeastern, northern and central western China, accompanied by increases in southern, central eastern and western China (Ding et al. 2007). Giorgi et al. (2002) found that aerosol-induced RF and surface cooling tend to inhibit precipitation over East Asia, although this effect is relatively small in their simulations. Indirect effects of sulfate largely inhibit precipitation, especially during the summer (Giorgi et al. 2003). With comprehensive types of aerosol considered in their climate model, Qian et al. (2003) found little effect of aerosol on precipitation. Some simulations relate changes in precipitation in East Asia to the effects of absorption aerosol (Menon et al. 2002, Wu et al. 2004, 2008, Ramanathan et al. 2005), in spite of the uncertainty in the simulation of rainfall trends. In addition, the reduction of precipitation in east central China during the last $40 \mathrm{yr}$ is strongly correlated to high aerosol concentrations (Zhao et al. 2006). Gu et al. (2006) found that the inclusion of BC in their simulations did not produce the 'northern drought/southern flooding' pattern which has become frequent in China during the past 50 yr.

In the present study, the NCAR Community Atmospheric Model, Version 3.1 (CAM3) was used to estimate the combined direct effects of sulfate, BC, OC, and dust (including their RF), and the change in temperature and precipitation in East Asia. Section 2 describes the model and simulation strategy; Section 3 presents the results of a control simulation; Section 4 describes the results of $\mathrm{RF}_{\text {; }}$ Section 5 addresses the change of temperature and precipitation induced by aerosol; Section 6 discusses the conclusions.

\section{MODEL AND DATA}

CAM3 has a T42 spectral truncation (roughly $2.8^{\circ} \times$ $2.8^{\circ}$ horizontal resolution) and a 26 -level hybrid sigmapressure coordinate system (Collins et al. 2004), with the top of the model atmosphere at $3.54 \mathrm{hPa}$. Due to the distinct effect of sea surface temperature (SST) to East Asian climate, CAM3 is driven by a time-dependent monthly mean SST and sea-ice concentration dataset in the current simulation, with improved results compared to its old version (Hurrell et al. 2006). The major shortcoming of the model is that the simulated $500 \mathrm{hPa}$ heights are higher than the observed heights throughout the tropics and subtropics, which is consistent with a slight warm bias in the tropical troposphere (Hack et al. 2006).

In this study, two different CAM3 integrations from 1960-2000 are performed with the spin-up time of the first $10 \mathrm{yr}$. The control simulation $(\mathrm{CN})$ includes the forcing from sulfate, $\mathrm{BC}, \mathrm{OC}$, dust, and sea salt, and the aerosol simulation (AR) only includes the forcing from sea salt. The same parameters are used in both simulations, and concentrations of greenhouse gases are held constant at 1990 levels. To analyze the effects of total combined aerosol on climate, the $30 \mathrm{yr}$ mean from the CN simulation is compared to that of the AR.

The 3-dimensional time-dependent distributions of sulfate, BC, OC, and dust are included in the model with the prescribed dataset. The aerosol dataset is from an aerosol assimilation system (Collins et al. 2001, 2002) integrated for present-day conditions, in which the Model for Atmospheric Chemistry and Transport (MATCH) (Rasch et al. 1997) and an assimilation of satellite retrievals of aerosol optical depth are used including anthropogenic and natural sources for aerosol. The direct effects of tropospheric aerosols on solar fluxes and heating rates are included under the aerosol external mixture assumption, and indirect effects are not included in the model.

Figs. 1 \& 2 show the annual and seasonal aerosol optical depth at $550 \mathrm{~nm}$ wavelength used in the simulations, respectively; the annual mean reaches a maximum of 0.27 in the middle reaches of the Yangtze River, and the Yellow and Huai River basins. The greatest optical depth is in the low reaches of the Yangtze River in spring with a maximum of 0.4 ; the maximum moves northward to the Yellow and Huai River basins in summer. In autumn and winter, the greatest optical depth lies in the Sichuan Basin, with maxima of 0.24 and 0.45 , respectively. The modeling results agree with satellite monitoring data (Collins et 

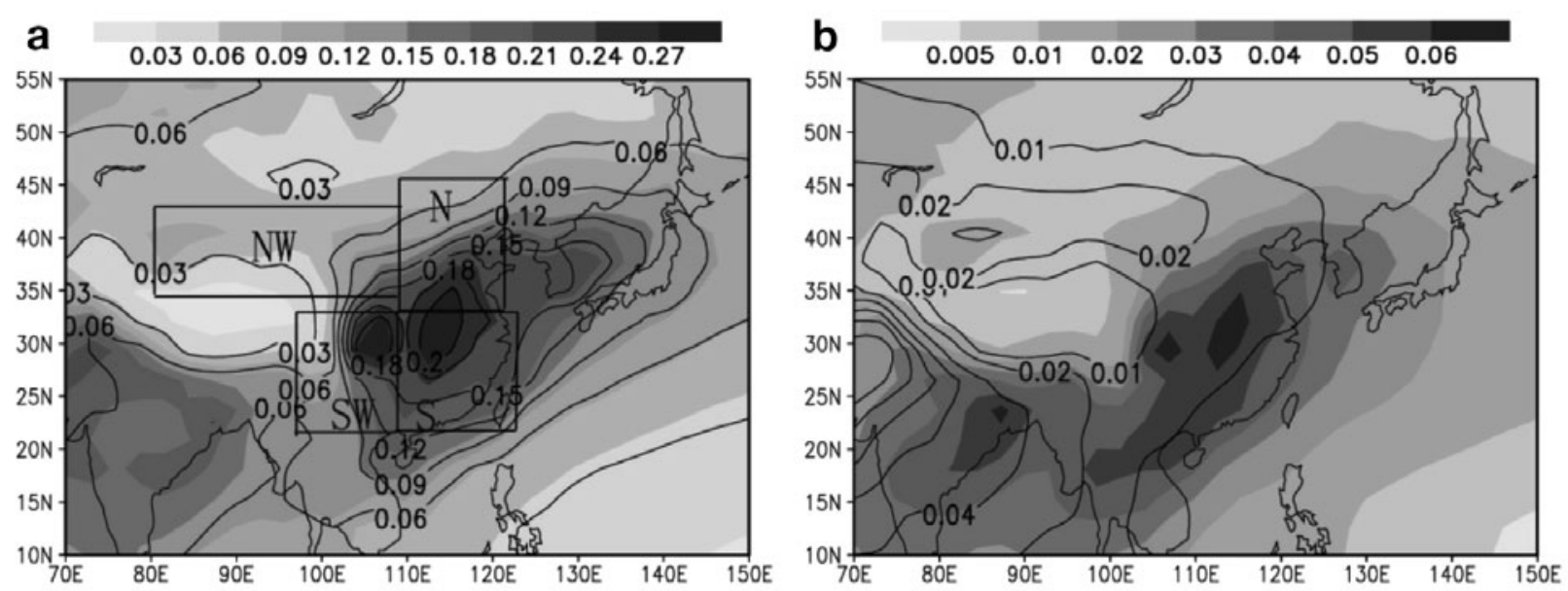

Fig. 1. Annual mean aerosol optical depth in East Asia at $550 \mathrm{~nm}$ wavelength in the simulation. (a) Annual mean of total combined aerosol (shaded) and sulfate (contours); frames show the 4 study regions described in Tables $1 \& 2$. (b) Annual mean of sum of black carbon (BC) and organic carbon (OC) (shaded) and dust (contours)
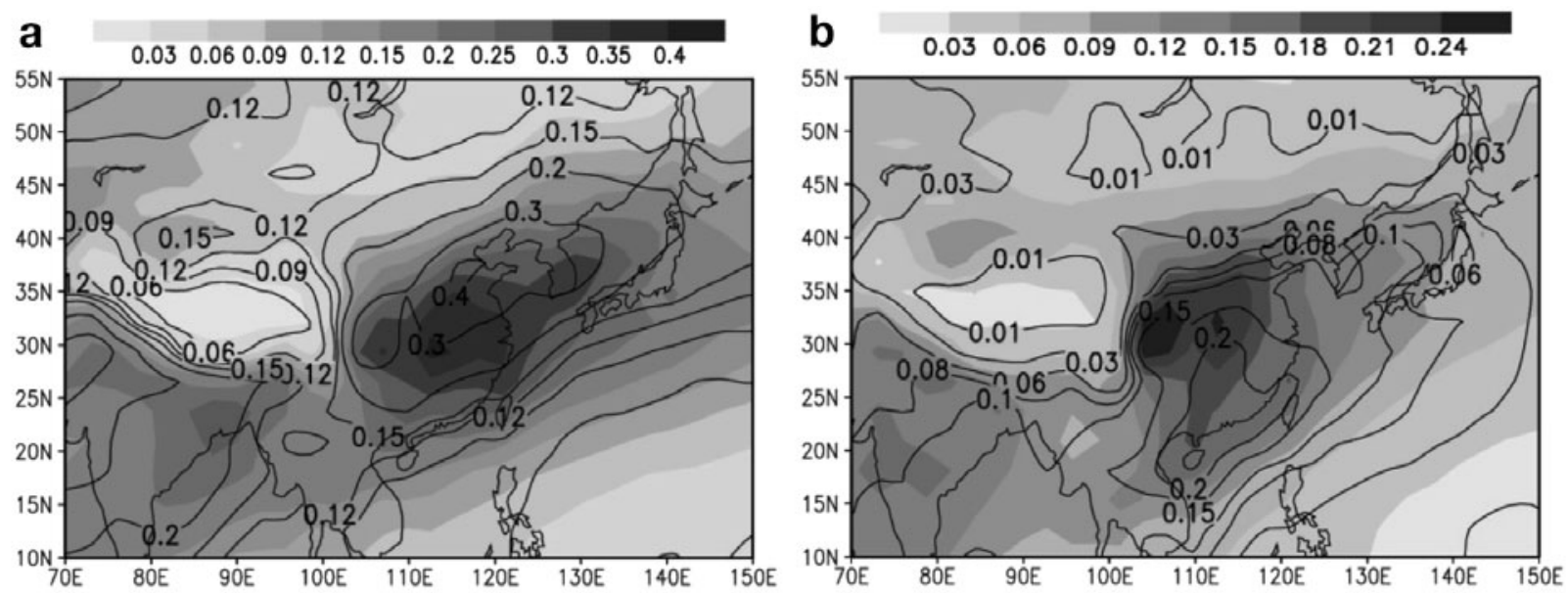

Fig. 2. Seasonal change in aerosol optical depth in East Asia at $550 \mathrm{~nm}$ wavelength in the simulation. (a) Total combined aerosol in spring (shaded) and summer (contours). (b) Total combined aerosol in autumn (shaded) and winter (contours)

al. 2001). Sulfate contributes the greatest proportion to total optical depth, followed by carbonaceous aerosol $(\mathrm{BC}+\mathrm{OC})$. Sulfate has a similar pattern to total combined aerosol in almost all domains. The pattern of carbonaceous aerosol is also similar to total combined aerosol, but carbon constitutes a smaller proportion of total aerosol in southern than in northern China. Dust aerosol is highest in western China and northern India, and lowest in eastern China. Optical depth of aerosol used in this simulation is listed in Table 1 ; the rectangles in Fig. 1a show the regions studied.

\section{CONTROL SIMULATION}

Evaluating the basic climatic simulations, Fig. 3 shows the simulated sea surface pressure and NCEP reanalysis data in winter and summer, respectively.
The pressure patterns agree with the reanalysis data in most parts of the model domain. However, the simulation is 4-6 hPa higher than the NCEP data, except for in the northwestern part of the domain in winter and in the western part in summer. Simulated geopotential heights at different levels are also represented well by the model (data not shown).

Table 1. Optical depth of aerosol components and total aerosol for the regions shown in Fig. 1, and for all China

\begin{tabular}{|lccccc|}
\hline & Sulfate & Carbon & Dust & Sea salt & Total \\
\hline North & 0.15 & 0.04 & 0.01 & 0 & 0.20 \\
Northwest & 0.06 & 0.01 & 0.02 & 0 & 0.09 \\
South & 0.13 & 0.04 & 0.01 & 0.01 & 0.19 \\
Southwest & 0.10 & 0.05 & 0.01 & 0 & 0.16 \\
All China & 0.09 & 0.03 & 0.02 & 0 & 0.14 \\
\hline
\end{tabular}



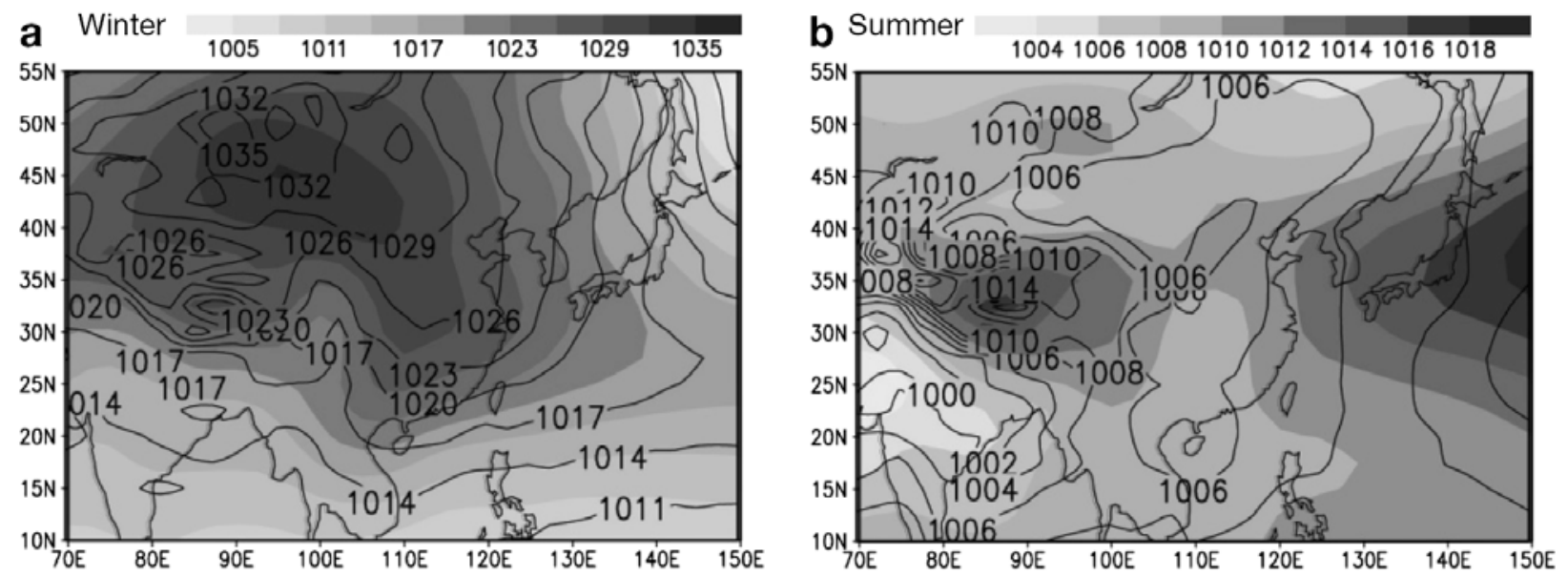

Fig. 3. Simulated sea surface pressure (hPa) (shaded) and NCEP data (contours) in (a) winter and (b) summer

The model also captures the pattern of skin temperature in winter and summer (Fig. 4). However, in winter the simulation is $2-4^{\circ} \mathrm{C}$ warmer than the NCEP data except for northern India, and the difference between simulations and observations is statistically significant in most parts of the Chinese mainland (data not shown). The results indicate low reliability of the temperature simulation for the Chinese mainland in winter, and further improvement is necessary. In summer the simulation is $2-4^{\circ} \mathrm{C}$ cooler than the NCEP data in northern and northeastern China, accompanied by the $2-6^{\circ} \mathrm{C}$ positive bias in other areas. The difference in summer is statistically insignificant in most regions (data not shown).

Grid rainfall data of the Global Precipitation Climatology Project (GPCP) is used to compare with the simulation results (Adler et al. 2003) (Fig. 5). For the total precipitation in summer, the observation data show that the main rainfall region lies in India and the vicinity of the Tibetan Plateau with a maximum of $11 \mathrm{~mm}$ $\mathrm{d}^{-1}$, and the simulation captures this despite a shift of the maximum rainfall center to the southwest corner of the domain. In addition, biases in northeastern and northwestern China are small. The pattern of total precipitation in summer (Fig. 5a) is mainly due to convective precipitation, especially in the southern part of the domain, and the maximum of large-scale precipitation, which is remarkably smaller than convective precipitation, lies in central China. The annual mean precipitation in the simulation agrees with the observations in most regions except for the difference in the coastal region of southern China, where the model fails to reproduce the rainfall center in Guangdong and Hainan provinces. Similarly, a significant proportion of annual total precipitation (Fig. 5d) is from convective precipitation for the region south of $30^{\circ} \mathrm{N}$.
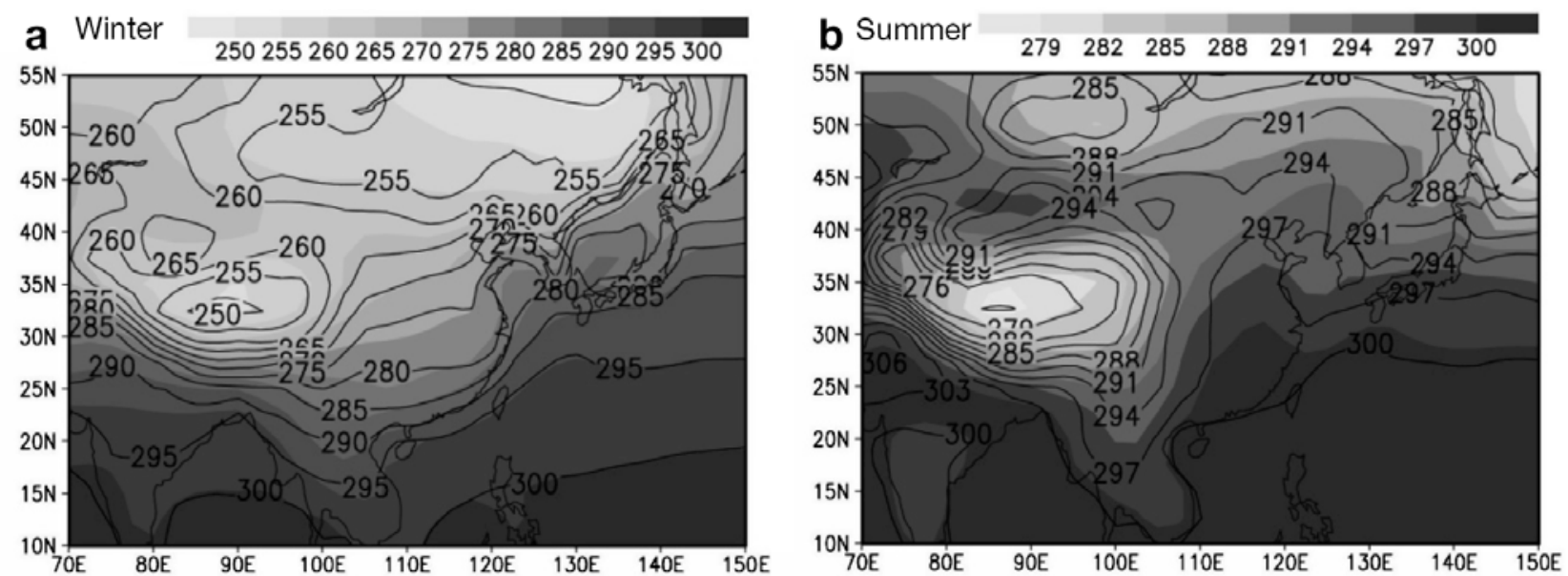

Fig. 4. Simulated sea surface temperature (skin temperature, in K) (shaded) and NCEP data (contours) in (a) winter and (b) summer 
Total precipitation

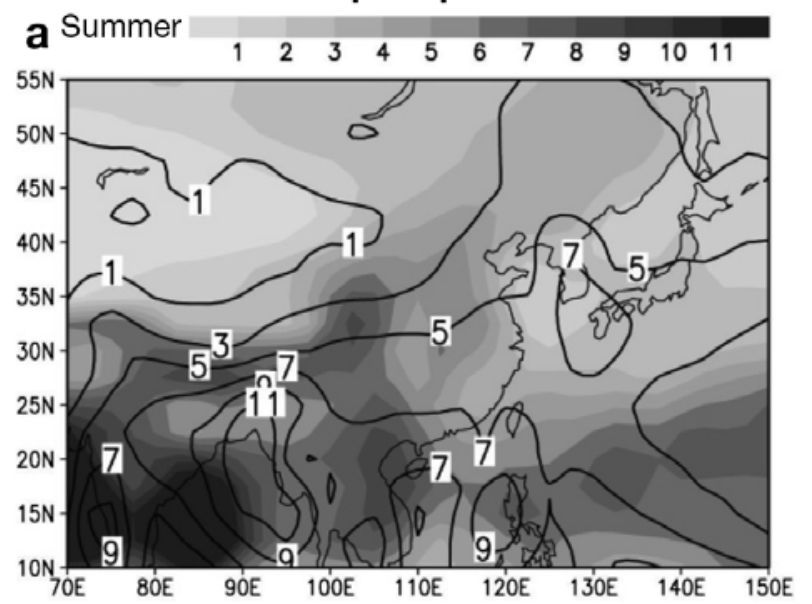

Convective and large-scale precipitation

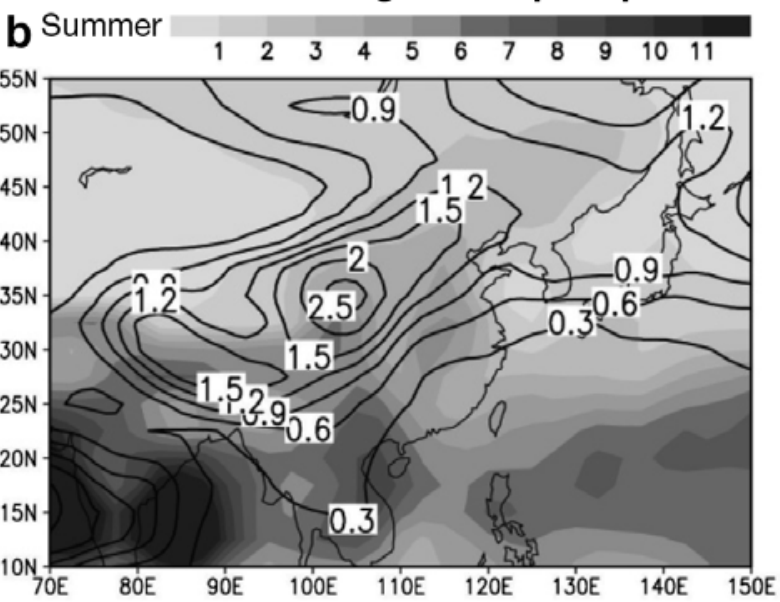

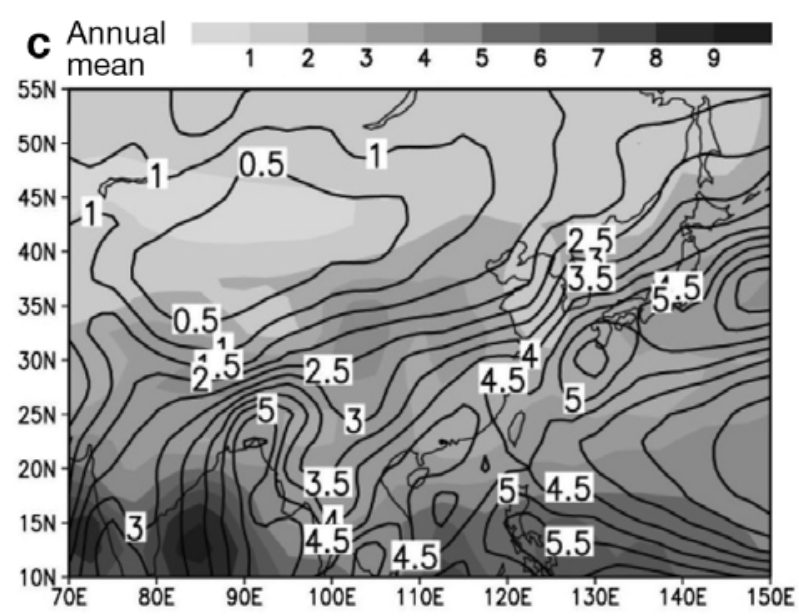

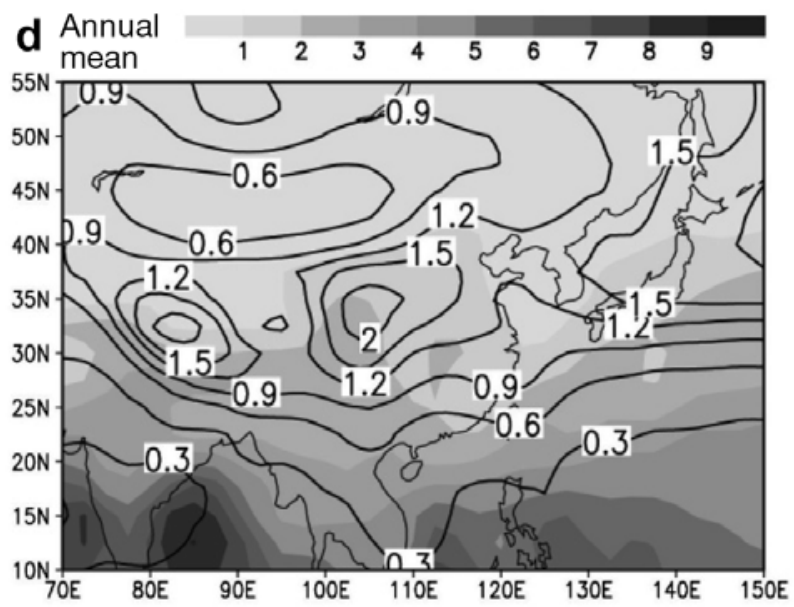

Fig. 5. Precipitation $\left(\mathrm{mm} \mathrm{d}^{-1}\right)(\mathrm{a}, \mathrm{b})$ in summer and $(\mathrm{c}, \mathrm{d})$ annual mean, from simulated and Global Precipitation Climatology Project (GPCP) data. $(\mathrm{a}, \mathrm{c})$ Total precipitation from simulation (shaded) and GPCP (contours); (b,d) convective (shaded) and large-scale precipitation (contours)

\section{RADIATIVE FORCING}

Annual mean RF of total combined aerosol at the top of the atmosphere (TOA) under all-sky conditions (Fig. 6a) is largely negative, except for some positive values over southern China and the northeastern part of the domain. RF at TOA is statistically significant only in northwestern China and India. Distinct surface dimming can be found in most regions in the domain under all-sky conditions, except for Japan and adjacent regions having positive RF. Surface dimming can exceed $10 \mathrm{~W} \mathrm{~m}^{-2}$ in central and northern China, with a maximum of $15 \mathrm{~W} \mathrm{~m}^{-2}$. The most distinct dimming occurs in the Indian Peninsula, with $>25 \mathrm{~W} \mathrm{~m}^{-2}$. Statistically significant regions cover almost the entire domain, except for the Tibetan Plateau, Japan and adjacent areas, and areas close to the Philippines, which enhances the reliability of the observed dimming effects in East Asia. Surface dimming can be due to (1) scattering and absorption of radiation by aerosol, and (2) absorption enhancement in the air column from multiple reflection between the clouds and aerosol.

$\mathrm{RF}$ is negative under clear sky conditions. Extreme $\mathrm{RF}$ at TOA occurs in the middle and low reaches of the Yangtze River, with $-12 \mathrm{~W} \mathrm{~m}^{-2}$, and $\mathrm{RF}$ exceed $-6 \mathrm{~W} \mathrm{~m}^{-2}$ throughout eastern China. The statistically significant regions almost cover the whole domain except for the Tibetan Plateau. RF at the surface under clear sky conditions has a similar pattern as that at TOA, but is twice as high in most regions. Significant dimming in China can reach $-25 \mathrm{~W} \mathrm{~m}^{-2}$ in the lower Yangtze River, and the maximum can exceed $-30 \mathrm{~W}$ $\mathrm{m}^{-2}$ in some parts of India. Surface dimming under allsky is weaker than it under clear sky conditions in most regions, probably due to increased absorption in the air column resulting from multiple reflection between 

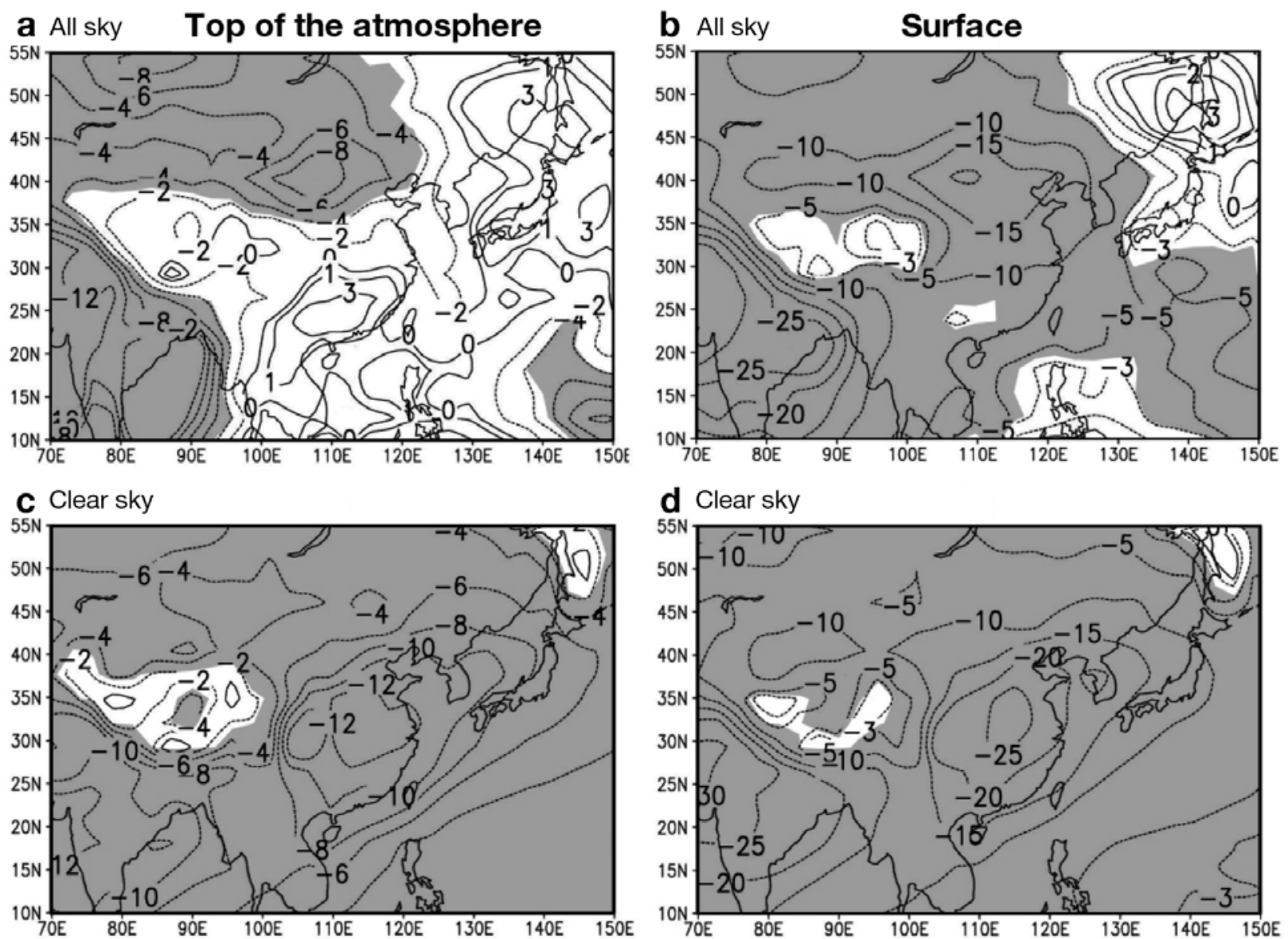

Fig. 6. Annual mean of radiative forcing $\left(\mathrm{W} \mathrm{m}^{-2}\right)$ induced by total combined aerosol. Shaded: Areas with significant difference $(t$-test, $\mathrm{p}=0.90)$

cloud and aerosol layers (Haywood \& Shine 1997, Liao \& Seinfeld et al. 1998).

Regional mean RF under clear sky is more distinct than all-sky conditions, and surface dimming is stronger than RF at TOA (Table 2). The most distinct RF occurs in northern China, especially for surface dimming. For

Table 2. Radiative forcing (annual mean, $\mathrm{W} \mathrm{m}^{-2}$ ) induced by total combined aerosol for the regions shown in Fig. 1, and for all China; values in parentheses are for clear sky

\begin{tabular}{|lcrc|}
\hline \multicolumn{1}{c}{ Solar } & Infrared & Total \\
\hline \multicolumn{1}{l}{ Top of the atmosphere } & & \\
North & $-3.18(-9.54)$ & $-0.36(-0.93)$ & $-3.54(-10.47)$ \\
Northwest & $-2.16(-3.83)$ & $-0.71(-0.75)$ & $-2.87(-4.58)$ \\
South & $-0.45(-9.56)$ & $1.73(-0.03)$ & $1.28(-9.59)$ \\
Southwest & $-0.21(-8.12)$ & $0.75(-0.31)$ & $0.55(-8.43)$ \\
All China & $-2.59(-7.04)$ & $-0.34(-0.63)$ & $-2.92(-7.67)$ \\
Surface & & & \\
North & $-11.37(-18.20)$ & $-2.55(-1.80)$ & $-13.91(-19.99)$ \\
Northwest & $-6.14(-8.07)$ & $-2.36(-1.46)$ & $-8.51(-9.53)$ \\
South & $-7.20(-16.45)$ & $0.26(-0.08)$ & $-6.94(-16.52)$ \\
Southwest & $-7.44(-15.51)$ & $0.09(-0.17)$ & $-7.35(-15.68)$ \\
All China & $-9.23(-13.92)$ & $-1.49(-1.01)$ & $-10.73(-14.92)$ \\
\hline
\end{tabular}

China overall, annual mean surface dimming is $11 \mathrm{~W}$ $\mathrm{m}^{-2}$ under all-sky and $15 \mathrm{~W} \mathrm{~m}^{-2}$ under clear sky conditions; based on the difference between RF at TOA and the surface, the RF of the atmosphere is $7.25 \mathrm{~W} \mathrm{~m}^{-2}$ under clear sky and $7.81 \mathrm{~W} \mathrm{~m}^{-2}$ under all-sky conditions. The difference of $0.56 \mathrm{~W} \mathrm{~m}^{-2}$ between clear and all-sky conditions is possibly due to absorption enhancement in the air column between clouds and aerosol. On the other hand, the direct absorption of aerosol can account for the bias between RF at TOA and SRF under clear sky conditions, which corresponds to RF of the atmosphere $\left(7.25 \mathrm{~W} \mathrm{~m}^{-2}\right.$ for the Chinese mainland). In the two parts of atmospheric RF, the direct absorption by aerosol is much larger than the enhancement absorption by the air column between the cloud and the aerosol layer. Solar RF is a considerable proportion of total RF at both TOA and surface, and the proportion of infrared RF in total RF is $<10 \%$ for most regions (Table 2), which shows that aerosol leads to the warming of the daytime temperature. This effect is different from greenhouse gases, which lead to increases in both day- and nighttime temperatures. The dimming at the surface in solar bands is nearly the 
same as the net RF under both clear and all-sky conditions, which reflects that the optical character of total combined aerosol mainly leads to scattering. This can be explained by the bigger proportion of sulfate in total combined aerosol.

$\mathrm{RF}$ at TOA and the surface is negative in all seasons (Fig. 7). Seasonal changes in RF are similar in northern and northwestern China, with highest RF in summer and lowest in winter. Seasonal trends are weaker in southern and southwestern China, with highest RF values in spring and lowest in summer. Absolute values are greater at the surface (Fig. 7b) than at TOA (Fig. 7a), due to absorption by aerosol.

\section{CHANGE IN TEMPERATURE AND PRECIPITATION}

\subsection{Temperature}

Temperature changes induced by RF are shown in Fig. 8. Maximum and mean skin temperatures have similar patterns, with extreme cooling on the Tibetan Plateau (up to -4 and $-1.5 \mathrm{~K}$, respectively). The change in maximum and mean skin temperatures is statistically significant in most of the domain except on the Tibetan Plateau, and it is similar to the pattern in RF (Fig. 6). The change in minimum temperature (Fig. 8b) is in agreement with Fig. 8a,c, except that significant decreases occur in southern and southeastern China; decreases are generally -0.5 to $-1 \mathrm{~K}$. The change in minimum temperature is statistically insignificant in most central and northern regions in the domain. The temperature range changes by -1.5 to $-2 \mathrm{~K}$ in northern China, and -0.9 to $0.3 \mathrm{~K}$ in other regions (positive values in the western part of Xinjiang Province, eastern edge of the Tibetan Plateau, and part of northeastern China); the most notable decrease is $-3 \mathrm{~K}$ in India (Fig. 8d). However, changes are not significant. Sur- face air temperatures have a similar pattern to skin temperature and show much weaker changes induced by aerosol.

Overall, aerosol leads to a decrease in mean skin temperature in the western part of northwest and northeast China, mainly by a reduction in minimum temperature. A similar reduction is found in the Indian Peninsula, southwestern, central, southern, northern and the eastern part of northwest China. The decrease in minimum temperature is also more remarkable than that in maximum temperature in these regions. Also, the regions with a significant reduction in maximum temperature are much larger than in the case of minimum temperature, and the statistically significant regions of mean temperature are almost the same as the temperature decreased regions. This confirms that aerosol has a cooling effect in East Asia, which agrees with the negative RF (Fig. 6). The decrease in minimum temperature contributes distinctly to the reduction in mean temperature in the regions investigated (Table 3).

Skin temperature decreases in all months (Fig. 9), except for an increase in southwestern China in March. The strongest decreases are in January, April and October in northern and northwestern China $(-1.5 \mathrm{~K}$ in northwest China in January), and in winter in southern and southwestern China. The reduction in temperature is more notable in autumn and winter.

Air column temperature (mass-weighted mean temperature) increases by $0.12 \mathrm{~K}$ in northern India, northeastern and northwestern China, and southern Japan. Temperature decreases in other regions, with extreme values of $-0.2 \mathrm{~K}$ in the northern edge of the domain and -0.06 to $-0.12 \mathrm{~K}$ in the Indian and Indochinese peninsulas. There is a significant reduction in February and August for all areas, and weak temperature rises in March and April for all regions and in October for all regions except northern China (Fig. 10). The rise
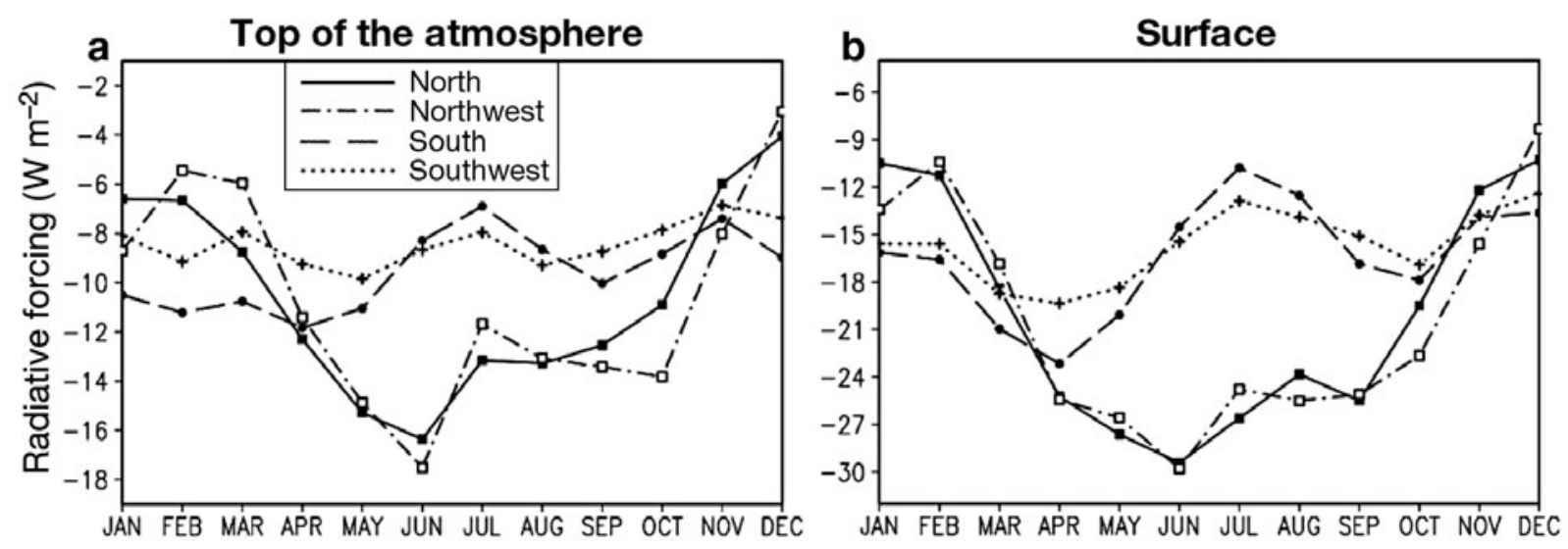

Fig. 7. Seasonal change in radiative forcing $\left(\mathrm{W} \mathrm{m}^{-2}\right.$ ) under clear sky conditions averaged over the simulation period. (a) Top of the atmosphere, (b) surface 

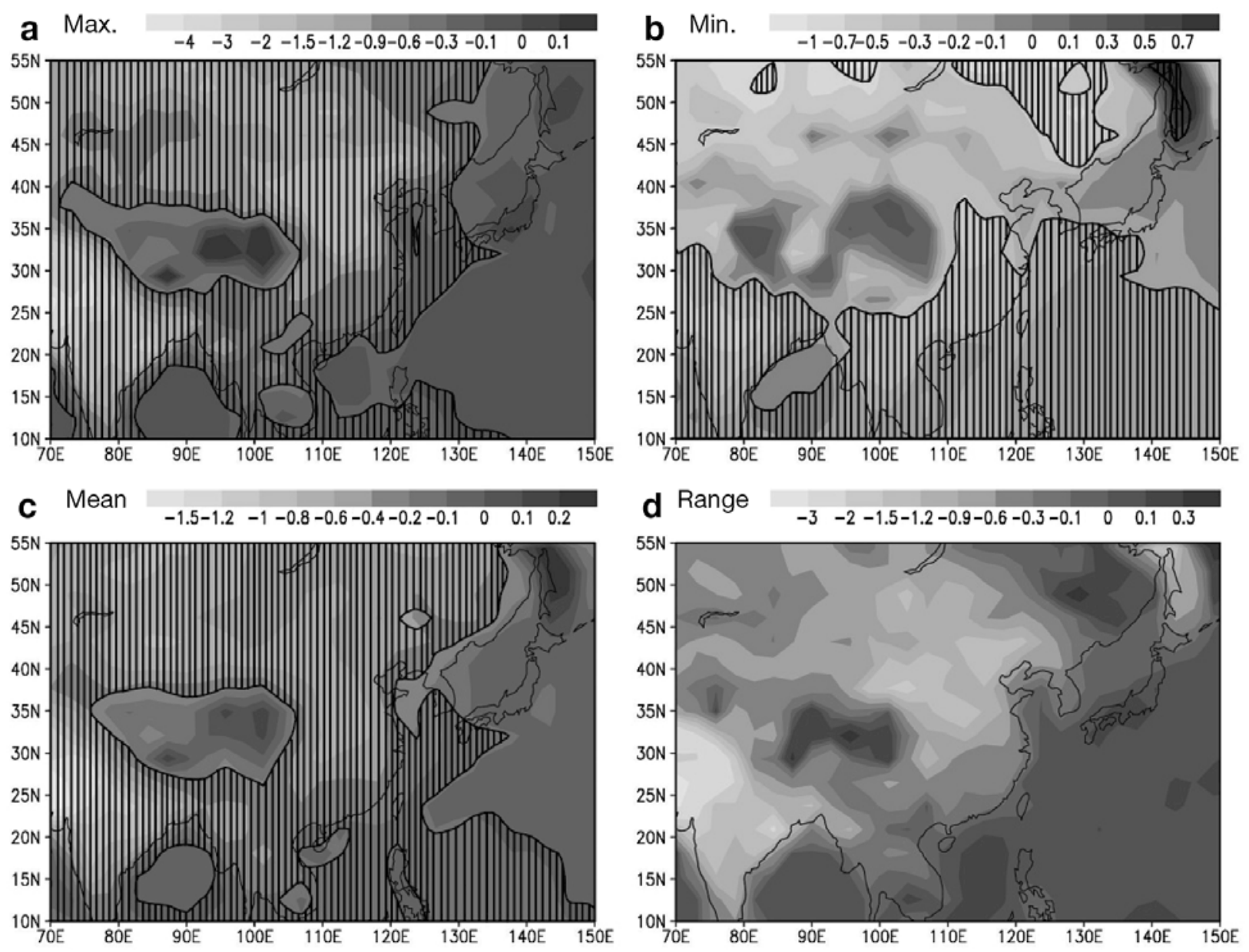

Fig. 8. Change in (a) maximum, (b) minimum and (c) mean skin temperature, and (d) monthly range of skin temperature (K) averaged over the simulation period. Hatched: statistically significant change $(2$-tailed $t$-test, $\mathrm{p}=0.90)$

of annual mean air column temperature is $0.05 \mathrm{~K}$ in northern and northwestern China, and a weak decrease in southern and southwestern China (Table 3). There is a $0.01 \mathrm{~K}$ rise in air column temperature in the Chinese mainland, accompanied by a $0.34 \mathrm{~K}$ reduction in skin temperature.

Change in temperature can affect atmospheric stability. Air temperature is reduced close to the surface and tropopause, and increases in the middle of troposphere
(Fig. 11). The strongest decrease in the bottom of the atmosphere lies in northern China, while the increase is most noticeable in northern and northwestern China. These changes near the surface and in the middle of the troposphere increase the stability in the lower atmosphere, especially in northern China, while the stability in the upper troposphere is reduced due to the temperature rise near the tropopause. The changes in atmospheric stability may affect convection and precipitation.

Table 3. Changes in temperature (monthly mean, maximum and minimum) and precipitation (annual mean) induced by total combined aerosol for the regions shown in Fig. 1, and for all China

\begin{tabular}{|c|c|c|c|c|c|c|c|c|c|}
\hline & \multicolumn{3}{|c|}{ Skin temperature (K) } & \multirow{2}{*}{$\begin{array}{c}\text { Air } \\
\text { temp. }(\mathrm{K})\end{array}$} & \multicolumn{2}{|c|}{ Water vapor } & \multicolumn{3}{|c|}{ Precipitation $\left(\mathrm{mm} \mathrm{d}^{-1}\right)$} \\
\hline & Mean & Max. & Min. & & $(\%)$ & $\begin{array}{l}\text { Content } \\
\left(\mathrm{g} \mathrm{kg}^{-1}\right)\end{array}$ & $\begin{array}{c}\text { Large } \\
\text { scale }\end{array}$ & Convective & Total \\
\hline North & -0.53 & -0.37 & -1.26 & 0.05 & 1.62 & 0.02 & 0 & -0.12 & -0.12 \\
\hline Northwest & -0.31 & -0.07 & -0.67 & 0.05 & 2.20 & 0.02 & 0.03 & -0.04 & -0.01 \\
\hline South & -0.29 & -0.29 & -0.45 & -0.02 & -1.60 & -0.05 & -0.05 & -0.24 & -0.29 \\
\hline Southwest & -0.31 & -0.27 & -0.57 & -0.03 & -1.38 & -0.04 & -0.07 & -0.23 & -0.30 \\
\hline All China & -0.34 & -0.20 & -0.71 & 0.01 & 0.47 & 0 & -0.01 & -0.12 & -0.13 \\
\hline
\end{tabular}




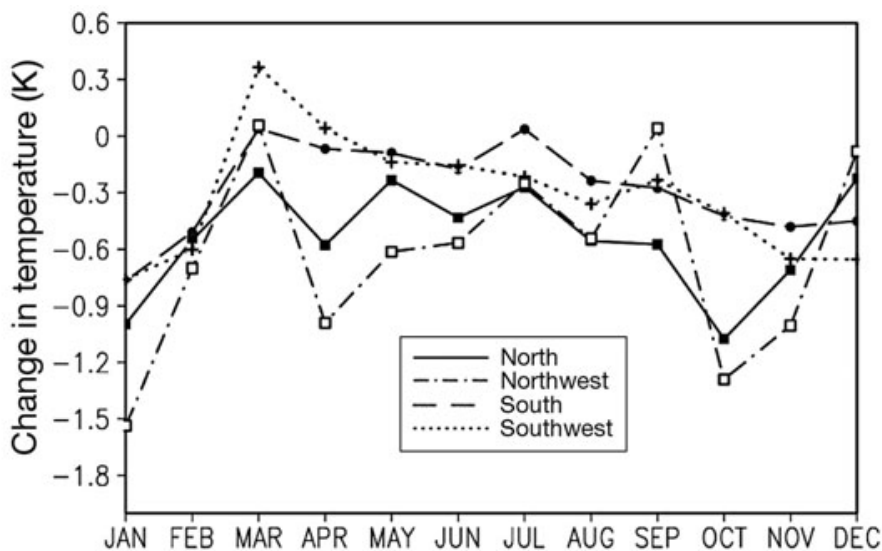

Fig. 9. Seasonal change in skin temperature (K) averaged over the simulation period

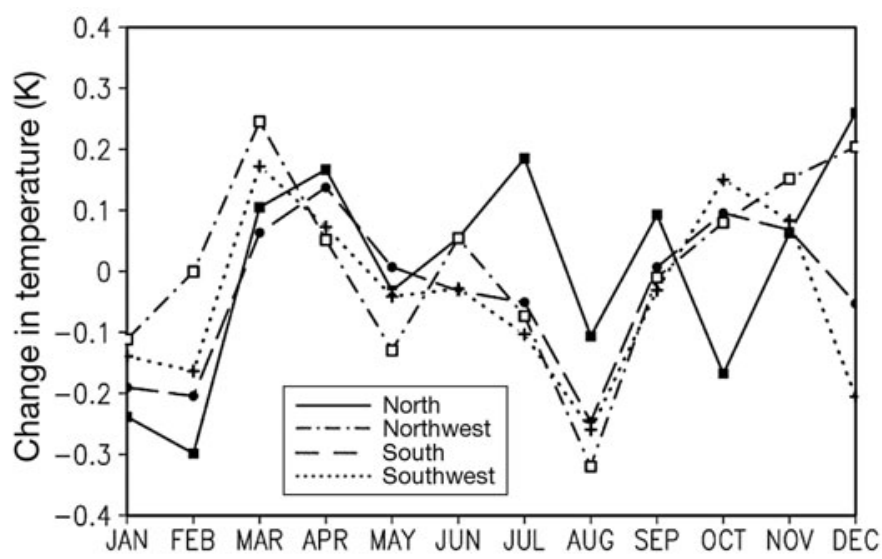

Fig. 10. Seasonal change in air column temperature (K) averaged over the simulation period

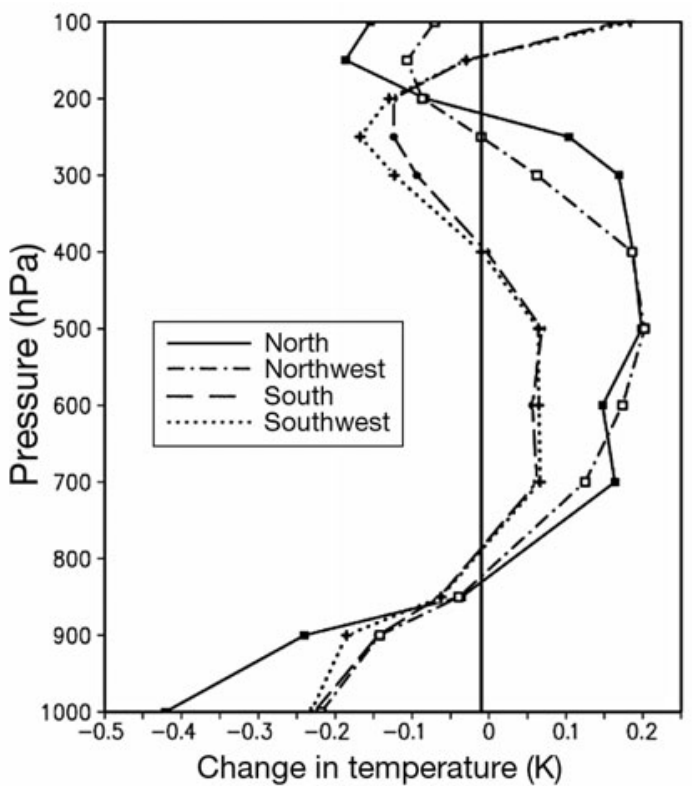

Fig. 11. Vertical profiles of change in air temperature $(\mathrm{K})$ averaged over the simulation period (perpendicular line: mean change)

\subsection{Vapor content}

Aerosol-induced RF leads to changes in temperature and atmospheric stability, which, in turn, lead to changes in vapor content and precipitation. A marked decrease in vapor content is found in most parts south of the Yellow River, and in northern northeast China, with a decrease up to -2 to $-3 \%$ (Fig. 12a). There is also a strong reduction in the coastal regions of southern China ( -3 to $-5 \%$ ). North of the Yellow River, there is an increase of 2 to $5 \%$, especially in northern and and northwestern China. The most distinct increase in vapor content lies in northern India with 7 to $10 \%$.

Change of streamline on $850 \mathrm{hPa}$ is shown in Fig. 13, which is similar to Fig. 12a. There is an anti-cyclone of vapor transport centered over Bengal induced by aerosol, which covers southwestern and part of southern China. It reduces vapor flux from the Bengal Sea to eastern China, but increases vapor flux to the Tibetan Plateau, Sichuan Basin and northern China. This is consistent with the significant decrease in vapor content in most of southern China. Another anti-cyclone of vapor transport is located in the east of the domain.
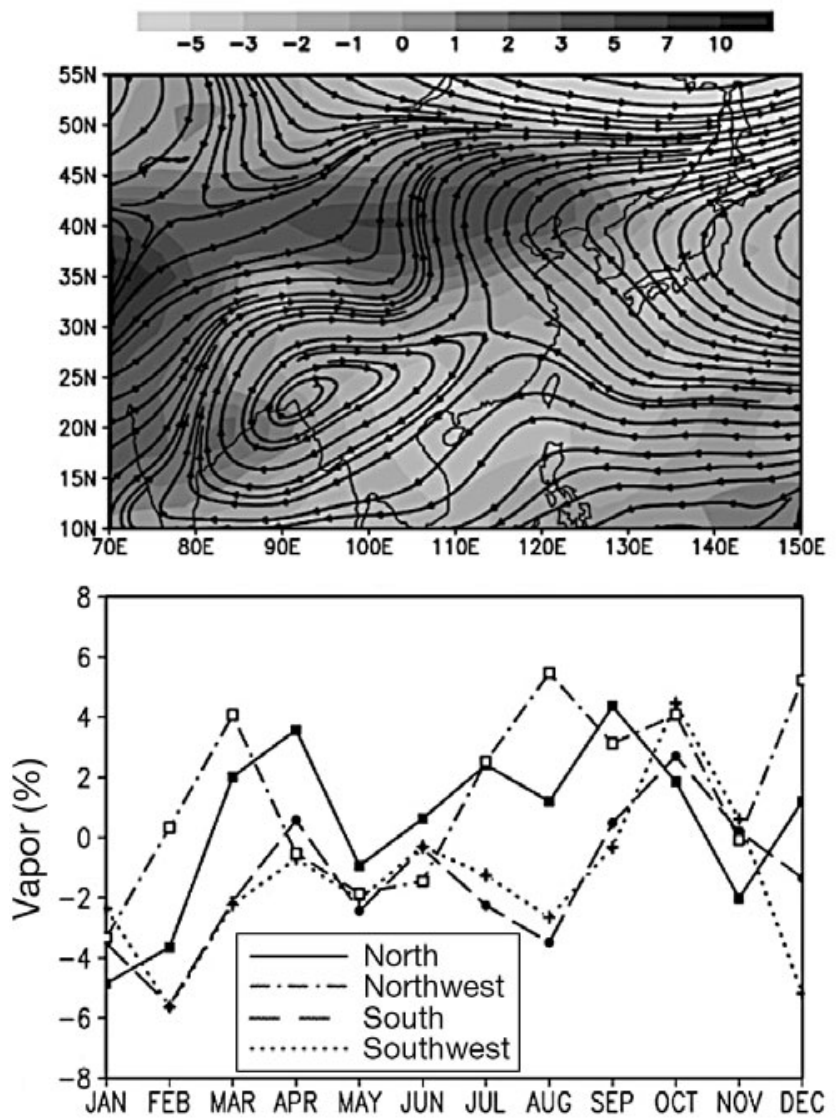

Fig. 12. (a) Change in vapor column burden (shaded, \%) and vapor flux (arrows) below $500 \mathrm{hPa}$. (b) Seasonal change in vapor content $(\%)$ 


\section{Temperature $(0.1 \mathrm{~K})$}

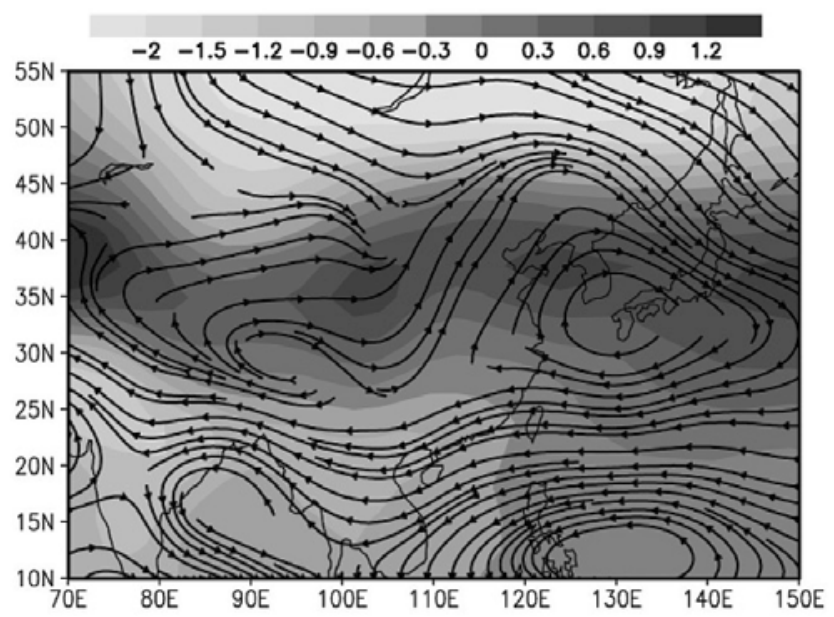

Fig. 13. Change in air column temperature (unit: $0.1 \mathrm{~K}$ ) and air flow (arrows) on $850 \mathrm{hPa}$ averaged over simulation period

Stronger southeasterly wind at its southwestern edge is accompanied by vapor increase in northern China. The decrease in vapor content in the eastern part of the domain may be caused by the reinforced northwesterly wind from Siberia. A belt of increased vapor content extends from the northwest edge of the Tibetan Plateau to most of northern China, which correlates to the enhancement of southerly wind from the Indian Ocean. This is a catabatic factor to the drought in northwestern China in recent years. Vapor content increases in northern and northwestern China and decreases in southern and southwestern China (Table 3).

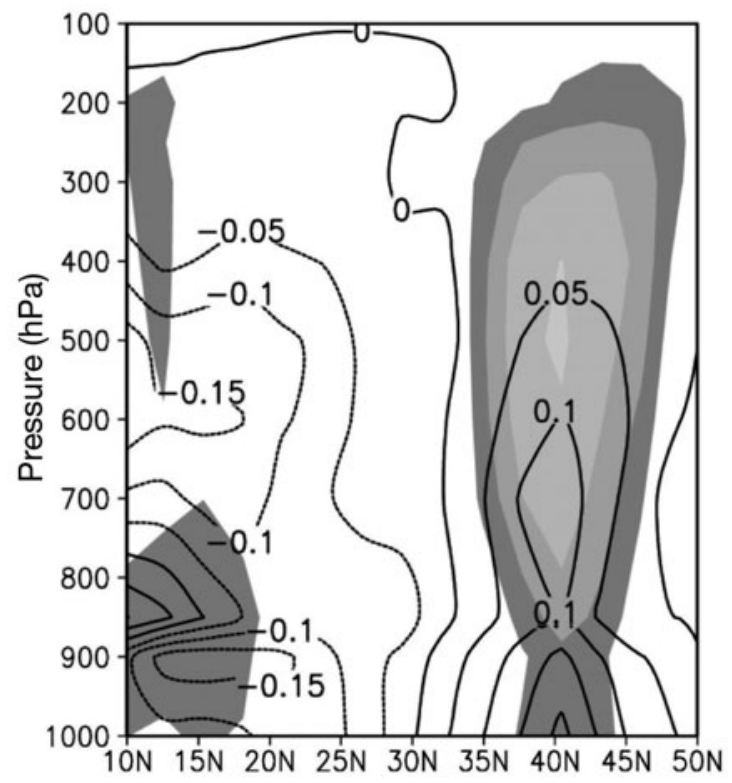

Fig. 14. Longitudinal cross section of change in vapor content $\left(\mathrm{g} \mathrm{kg}^{-1}\right)$ averaged over $100^{\circ}-120^{\circ} \mathrm{E}$ (contours) and ascending motion $\Omega$ (shaded, $\mathrm{hPa} \mathrm{s}^{-1}$ ) averaged over the simulation period

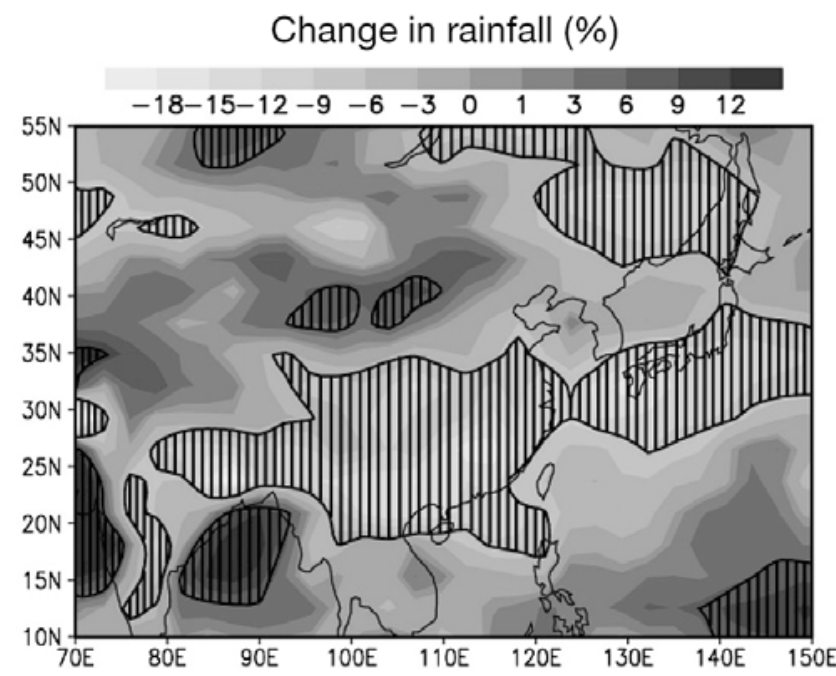

Fig. 15. Change in total rainfall (\%) averaged over the simulation period. Hatched: statistically significant change (2-tailed $t$-test, $\mathrm{p}=0.90$ )

Vapor content is reduced almost in all months in southern and southwestern China, with a maximum decrease in February, and it is generally increased in northern and northwestern China with maxima in September and August, respectively (Fig. 12b). In the monsoon season, changes in vapor content in southern and southwestern China are weaker than in the drought season.

Vapor increases in northern and decreases in southern China (Fig. 14), opposite to the trends of flooding in southern and drought in northern China in recent years. The greatest change lies in the middle and bottom of the troposphere, especially below $800 \mathrm{hPa}$. In the region between 35 and $45^{\circ} \mathrm{N}$, the vapor content is increased near the surface with a maximum of $0.2 \mathrm{~g} \mathrm{~kg}^{-1}$. Ascending motion occurs in the south to $20^{\circ} \mathrm{N}$, and north of $35^{\circ} \mathrm{N}$, which indicates that in most parts of the southern Chinese mainland, aerosol induces a descending motion accompanying the reduction of vapor content in these regions. This pattern of vapor content and vertical motion should reduce rainfall in southern China, while increasing rainfall in northern China.

\subsection{Precipitation}

The change of precipitation is one of the principal effects induced by aerosol. In recent years, southern China has experienced more, and northern China has experienced less precipitation, due to a weakening of the monsoon. This is possibly related to BC aerosol (Menon et al. 2002). The weakening of the Indian monsoon due to $\mathrm{ABC}, \mathrm{BC}$ and $\mathrm{OC}$ aerosol is considered 


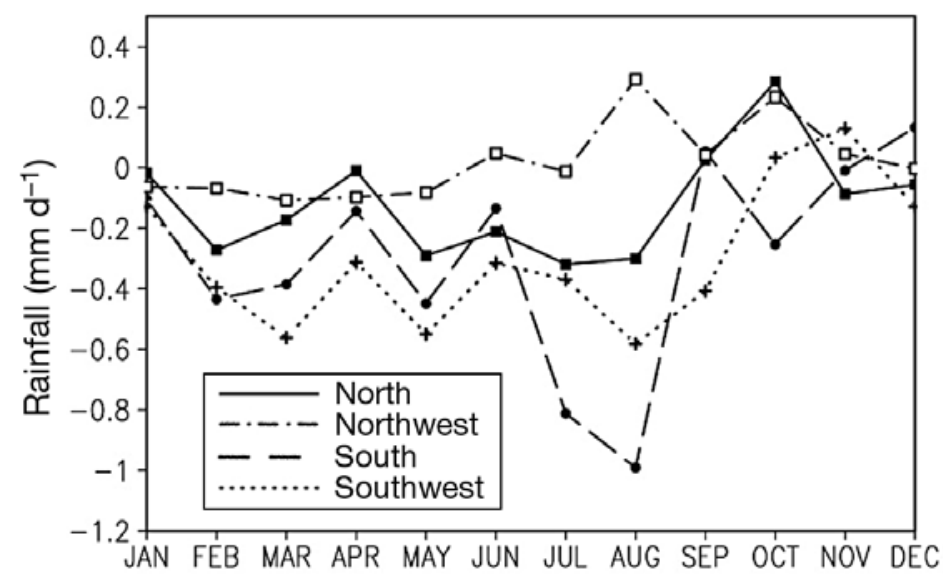

Fig. 16. Seasonal change in total rainfall $\left(\mathrm{mm} \mathrm{d}^{-1}\right)$ averaged over the simulation period

responsible for changes in Indian monsoon rainfall (Ramanathan et al. 2005) and absorption aerosol, especially BC, may affect monsoon rainfall in East and South Asia.

The changes in total precipitation pattern (Fig. 15) agree with the changes in vapor content (Fig. 12), with increasing moisture in northern and northwestern China and less moisture in southern and northeastern China. Precipitation increases $>3 \%$ are found in western India, the Bengal Sea, most of northwestern and northern China, with a maximum of $12 \%$.

Precipitation decreases in northeastern China and regions south of $35^{\circ} \mathrm{N}$, including central, southern and southwestern China with typical values between -6 and $-12 \%$. The belt with increased rainfall in northwestern China results from large-scale rainfall, whereas the increase in eastern India is mainly from convective precipitation (data not shown). The precipitation decrease in southern and northeastern China is due to a reduction in both large-scale and convective rainfall. Rainfall decreases throughout most of the year in northern and northwestern China (Fig. 16), and the main difference among these regions occurs in the monsoon season. In northwestern China, rainfall increases in summer and autumn, and in northern China there is a weak increase in April and autumn. Rainfall is reduced in almost all months in southern and southwestern China, especially in August. The decrease in total rainfall is mainly due to the decrease in convective precipitation (Table 3). Increases in large-scale precipitation are found only in northwestern China. The opposite trends between our results and the results when only $\mathrm{BC}$ aerosol is considered (Menon et al. 2002, Wu et al. 2008) can be related to the difference in optical characters between BC and total combined aerosol, which indicates some of the difficulties in evaluating the effects of aerosol on climate.

\section{CONCLUSIONS}

We performed global climate simulations, and analyzed direct RF of total combined aerosol and its regional climatic effects over East Asia. The main results are:

(1) RF at TOA under clear sky conditions is negative. RF under all-sky conditions is weaker than under clear sky conditions in most regions. Distinct surface dimming is found with the simulated negative RF at the surface, and the strongest surface dimming can exceed 30 and $25 \mathrm{~W} \mathrm{~m}^{-2}$ under clear and all-sky conditions, respectively.

(2) Aerosol cools the surface by negative RF in most regions of the domain. It leads to a decrease in mean skin temperature of $-1.5 \mathrm{~K}$ in most parts of East Asia. Air column temperature is also affected by aerosol. In northern India, northwestern China, and southern Japan the temperature increases by $0.12 \mathrm{~K}$, with centers in northern India, eastern northwest China, and the Bohai Sea Basin. Temperature is reduced by $0.2 \mathrm{~K}$ in the northern edge of the domain. In general, temperature is decreased close to the surface and the tropopause, and increased in the middle of troposphere, increasing stability in the lower atmosphere.

(3) Vapor content and precipitation increase in northern and northwestern China, which is opposite to the trends of southern flooding and northern drought in China in recent years. Precipitation increases mainly in eastern and western India, and in most of northwestern China, with a maximum close to $12 \%$, while decreases appear in southern, southeastern and northeastern China, with a maximum of $-18 \%$.

Our results are affected by some limitations: (1) The indirect effect of aerosol is not accounted for. (2) Aerosol effects on SST are not included; aerosol can affect the SST gradient in the Indian Ocean and further affect the Indian Monsoon (Ramanathan et al. 2005), and interactions between SST and aerosol should be considered with coupled climate and ocean model systems in the future. (3) We excluded nitrate and ammonium aerosol in this simulation, which also have a considerable optical depth, and we only provide simulation results under an external mixture instead of internal mixture among these aerosols, which can change their radiative properties and thus induce different climatic effects.

Acknowledgements. The study was sponsored by the National Key Program for Developing Basic Sciences of China (No. 2006CB400506), and KZCX2-YW-Q11-03 and the Hundred Talents Program (Aerosol Characteristics and Climatic Impact) of the Chinese Academy of Sciences; the Chinese Nat- 
ural Science Foundation (40975092); the Natural Science Foundation (2009CD021) and the Foundation of Younger Scholars in Science and Technology (2009CI046) of Yunnan Province; and the opening project (LPM2008012) of the Institute of Plateau Meteorology Chinese Meteorological Administration. We thank Dr. Huiling Yuan for improving the English. This article was greatly improved by the comments of the anonymous reviewers.

\section{LITERATURE CITED}

Adler RF, Huffman GJ, Chang A, Ferraro R and others (2003) The Version-2 Global Precipitation Climatology Project (GPCP) monthly precipitation analysis (1979-present). J Hydrometeorol 4:1147-1167

Collins WD, Rasch PJ, Eaton BE, Khattatov BV, Lamarque JF, Zender CS (2001) Simulating aerosols using a chemical transport model with assimilation of satellite aerosol retrievals: methodology for INDOEX. J Geophys Res 106(D7): 7313-7336

Collins WD, Rasch PJ, Eaton BE, Fillmore DW, Kiehl JT, Beck CT, Zender CS (2002) Simulation of aerosol distributions and radiative forcing for INDOEX: regional climate impacts. J Geophys Res 107(D19):8028, doi:10.1029/2000 JD000032

Collins WD, Rasch PJ, Bouille BA, Hack JJ and others (2004) Description of the NCAR Community Atmosphere Model (CAM 3.0). Technical Report NCAR/TN-464+STR, National Center for Atmospheric Research, Boulder, CO

Ding Y, Ren G, Shi G, Gong P and others (2007) China's National Assessment Report on Climate Change (I): climate change in China and the future trend. Adv Clim Change Res 3(Suppl):1-5. Available at: www.climatechange.cn

Dumka UC, Satheesh SK, Pant P, Hedge P, Moorthy KK (2006) Surface changes in solar irradiance due to aerosols over central Himalayas. Geophys Res Lett 33:L20809, doi: 10.1029/2006GL027814

Forster P, Ramaswamy V, Artaxo P, Berntsen T and others (2007) Changes in atmospheric constituents and in radiative forcing. In: Solomon S, Qin D, Manning M, Chen Z and others (eds) Climate change 2007: the physical science basis. Contribution of Working Group I to the 4th assessment report of the Intergovernmental Panel on Climate Change. Cambridge University Press, Cambridge

$>$ Giorgi F, Bi X, Qian Y (2002) Direct radiative forcing and regional climatic effects of anthropogenic aerosols over East Asia: a regional coupled climate-chemistry/aerosol model study. J Geophys Res 107(D20):4439, doi:10.1029/ 2001JD001066

Giorgi F, Bi XQ, Qian Y (2003) Indirect vs. direct effects of anthropogenic sulfate on the climate of East Asia as simulated with a regional coupled climate-chemistry/aerosol model. Clim Change 58:345-376

> Gu Y, Liou KN, Xue Y, Mechoso CR, Li W, Luo Y (2006) Climatic effects of different aerosol types in China simulated by the UCLA general circulation model. J Geophys Res 111:D15201, doi:10.1029/2005JD006312

> Hack JJ, Caron JM, Yeager SG, Oleson KW, Holland MM, Truesdale JE, Rasch PJ (2006) Simulation of the global hydrological cycle in the CCSM Community Atmosphere Model version 3 (CAM3): mean features. J Clim 19: 2199-2221

> Han Z, Zhang R, Wang Q, Wang W, Cao J, Xu J (2008) Regional modeling of organic aerosols over China in summertime. J Geophys Res 113:D11202, doi:10.1029/2007JD 009436
Haywood JM, Shine KP (1997) Multi-spectral calculations of the radiative forcing of tropospheric sulfate and soot aerosols using a column model. Q J R Meteorol Soc 123: 1907-1930

- He K, Yang F, Ma Y, Zhang Q and others (2001) The characteristics of $\mathrm{PM}_{2.5}$ in Beijing, China. Atmos Environ 35: 4959-4970

Huang Y, Dickinson RE, Chameides WL (2006) Impact of aerosol indirect effect on surface temperature over East Asia. Proc Natl Acad Sci USA 103:4371-4376

> Hurrell JW, Hack JJ, Phillips AS, Caron J, Yin J (2006) The dynamical simulation of the Community Atmosphere Model version 3. J Clim 19:2162-2183

Jayaraman A, Gadhavi H, Ganguly D, Misra A, Ramachandran S, Rajesh TA (2006) Spatial variations in aerosol characteristics and regional radiative forcing over India: measurements and modeling of 2004 road campaign experiment. Atmos Environ 40:6504-6515

Liang F, Xia X (2005) Long-term trends in solar radiation and the associated climatic factors over China for 1961-2000. Ann Geophys 23:2425-2432

> Liao H, Seinfeld JH (1998) Effect of clouds on direct aerosol radiative forcing of climate. J Geophys Res 103: 3781-3788

> Luo YF, Lu DR, Zhou XJ, Li WL, He Q (2001) Characteristics of the spatial distribution and yearly variation of aerosol optical depth over China in last 30 years. J Geophys Res 106(D10):14501-14513

> Menon S, Hansen J, Nazarenko L, Luo Y (2002) Climate effects of black carbon aerosols in China and India. Science 297:2250-2253

> Qian Y, Giorgi F (1999) Interactive coupling of regional climate and sulfate aerosol models over eastern Asia. J Geophys Res 104(D6):6477-6499

Qian Y, Leung LR, Ghan SJ, Giorgi F (2003) Effects of increasing aerosol on regional climate change in China: observation and modeling. Tellus 55B:914-934

> Qian Y, Kaiser DP, Leung LR, Xu M (2006) More frequent cloud-free sky and less surface solar radiation in China from 1955 to 2000. Geophys Res Lett 33:L01812, doi: 10.1029/2005GL024586

Qian Y, Wang W, Leung LR, Kaiser DP (2007) Variability of solar radiation under cloud-free skies in China: The role of aerosols. Geophys Res Lett 34:L12804, doi: 10.1029/ 2006GL028800

Ramana MV, Ramanathan V, Kim D, Roberts GC, Corrigan CE (2007) Albedo, atmospheric solar absorption and heating rate measurements with stacked UAVs. Q J R Meteorol Soc 133:1913-1931

Ramanathan V, Crutzen PJ, Lelieveld J, Mitra AP and others (2001) Indian Ovean Experiment: an integrated analysis of the climate forcing and effects of the great Indo-Asian haze. J Geophys Res 106(D22):28371-28398

> Ramanathan V, Chung C, Kim D, Bettge T and others (2005) Atmospheric brown clouds: impacts on South Asian climate and hydrological cycle. Proc Natl Acad Sci USA 102: $5236-5333$

Ramanathan V, Li F, Ramana MV, Praveen PS and others (2007a) Atmospheric brown clouds: Hemispherical and regional variations in long-range transport, absorption, and radiative forcing. J Geophys Res 112:D22S21, doi: 10.1029/2006JD008124

> Ramanathan V, Ramana MV, Roberts G, Kim D, Corrigan C, Chung C, Winker D (2007b) Warming trends in Asia amplified by brown cloud solar absorption. Nature 448: 575-578

Rasch PJ, Mahowald NM, Eaton BE (1997) Representations of 
transport, convection, and the hydrologic cycle in chemical transport models: implications for the modeling of short-lived and soluble species. J Geophys Res 102(D23): $28127-28138$

Vinoj V, Badu SS, Satheesh SK, Moorthy KK, Kaufman YJ (2004) Radiative forcing by aerosols over the Bay of Bengal region derived from shipborne, island-based, and satellite (Moderate Resolution Imaging Spectroradiometer) observations. J Geophys Res 109:D052003, doi: 10.1029/2003JD004329

> Wang TJ, Min JZ, Xu YF, Lam KS (2003) Seasonal variations of anthropogenic sulfate aerosol and direct radiative forcing over China. Meteorol Atmos Phys 84:185-198

Wu J, Jiang WM, Fu CB, Su BK, Liu HN, Tang JP (2004) Simulation of the radiative effect of black carbon aerosols and the regional climate responses over China. Adv Atmos Sci 21:637-649

Wu J, Fu C, Xu Y, Tang JP, Wang W, Wang Z (2008) Simulation of direct effects of black carbon aerosol on tempera-

Editorial responsibility: Filippo Giorgi,

Trieste, Italy ture and hydrological cycle in Asia by a RCM. Meteorol Atmos Phys 100:179-193

Xu Q (2001) Abrupt change of the mid-summer climate in central east China by the influence of atmospheric pollution. Atmos Environ 35:5029-5040

Xu J, Bergin MH, Yu X, Liu G, Zhao J, Carrico CM, Baumann $\mathrm{K}$ (2002) Measurement of aerosol chemical, physical and radiative properties in the Yangtze delta region of China. Atmos Environ 36:161-173

- Ye B, Ji X, Yang H, Yao X and others (2003) Concentration and chemical composition of $\mathrm{PM}_{2.5}$ in Shanghai for 1-year period. Atmos Environ 37:499-510

> Zhai P, Zhang X, Wan H, Pan X (2005) Trends in total precipitation and frequency of daily precipitation extremes over China. J Clim 18:1096-1108

$>$ Zhao C, Tie X, Lin Y (2006) A possible positive feedback of reduction of precipitation and increase in aerosols over eastern central China. Geophys Res Lett 33:L11814, doi: 10.1029/2006GL025959

Submitted: September 1, 2008; Accepted: March 9, 2009 Proofs received from author(s): October 2, 2009 